Article

\title{
A Corrosion Sensor for Monitoring the Early-Stage Environmental Corrosion of A36 Carbon Steel
}

\author{
Dong Chen ${ }^{1}{ }^{1}$, Max Yen ${ }^{1}$, Paul Lin ${ }^{1}$, Steve Groff ${ }^{1}$, Richard Lampo ${ }^{2}$, Michael McInerney ${ }^{2}$ \\ and Jeffrey Ryan ${ }^{2}$
}

1 College of Engineering, Technology, and Computer Science, Indiana University-Purdue University, 2101 E Coliseum Blvd, Fort Wayne, IN 46805, USA; E-Mails: yens@ipfw.edu (M.Y.); lin@ipfw.edu (P.L.); groff.steve@gmail.com (S.G.)

2 U.S. Army Engineer Research \& Development Center, Construction Engineering Research Laboratory, P.O. Box 9005, Champaign, IL 61826, USA; E-Mails: Richard.G.Lampo@usace.army.mil (R.L.); Michael.K.McInerney@usace.army.mil (M.M.); Jeffrey.P.Ryan@usace.army.mil (J.R.)

* Author to whom correspondence should be addressed; E-Mail: chend@ipfw.edu; Tel.: +1-260-481-6356; Fax: +1-260-481-6281.

Received: 18 December 2013; in revised form: 1 August 2014 / Accepted: 4 August 2014 / Published: 8 August 2014

\begin{abstract}
An innovative prototype sensor containing A36 carbon steel as a capacitor was explored to monitor early-stage corrosion. The sensor detected the changes of the surface- rather than the bulk- property and morphology of A36 during corrosion. Thus it was more sensitive than the conventional electrical resistance corrosion sensors. After being soaked in an aerated $0.2 \mathrm{M} \mathrm{NaCl}$ solution, the sensor's normalized electrical resistance $\left(R / R_{0}\right)$ decreased continuously from 1.0 to 0.74 with the extent of corrosion. Meanwhile, the sensor's normalized capacitance $\left(C / C_{0}\right)$ increased continuously from 1.0 to 1.46. X-ray diffraction result indicates that the iron rust on A36 had crystals of lepidocrocite and magnetite.
\end{abstract}

Keywords: carbon steel; chloride; X-ray diffraction; rust; corrosion monitoring 


\section{Introduction}

Corrosion is a destructive attack on a metal such as carbon steel, aluminum, zinc and copper by chemical or electrochemical reactions with its environment [1]. It is a spontaneous process. If corrosion is not monitored and correctly fixed, it could threaten public welfares and people's lives [2]. Among various causes of corrosion, environmental factors are the most common ones because of ubiquitousness. Practically all environments are corrosive to some degree [3]. Some examples are air and moisture; fresh, distilled, salt, and mine waters; steam and other gases such as chlorine, ammonia, hydrogen sulfide, and fuel gases; mineral and organic acids $[3,4]$. Among these environmental factors, chloride is an important one. It is well known that chloride ions can cause passive layer breakdown and corrosion of metals $[5,6]$. Structures can be exposed to chloride ions through various means including deicing salts, fresh water, and a marine environment [7].

Manual inspection of corrosion is costly, low efficient, subjective and sometimes dangerous. It typically requires a large amount of time for professionals to travel and inspect each site. Especially when there are difficult-to-access or completely inaccessible areas, manual inspections are almost impossible. As a result, it is highly desirable to use corrosion sensors for automatic data collection, processing, and evaluation. Compared to manual inspections, automatic monitoring by corrosion sensors has significant advantages, such as promptness, comprehensiveness and efficiency. In addition, electrical signals from corrosion sensors are much easier to transmit, analyze and store than manual methods.

Conventional corrosion sensors are typically based on the mechanism of an increase in electrical resistance of iron with the degree of corrosion [8,9]. However, a lengthy response time is required to register a significant change in corrosion rate [10], because the percentage of the thickness change of the sensor has to be noteworthy. Detection of the early-stage environmental corrosion is of critical importance to maintain the integrity and the safety of structures and systems, because the corrosion can be a self-accelerating process when no corrosion inhibitors are present [11,12]. As a result, a prototype corrosion sensor has been explored in this study, in order to find the sensitive and systematic change in electrical properties of a metal surface (e.g., A36 carbon steel as investigated in this study) during the early-stage corrosion as it is exposed to a corrosive environment. A36 carbon steel is commonly used in steel bridges and other structures $[13,14]$. The definition of the early-stage corrosion is the mass change of the sensor is within $0.2 \%$ (or iron loss per exposed surface area is within $187.7 \mathrm{~g} / \mathrm{m}^{2}$ ) as explored in this study. The prototype sensor was essentially a capacitor composed of two parts: (i) the same metal with the same passivation/coating as the metallic structure or the system to be monitored; (ii) a corrosion-resistant conductor. The two parts were separated by air, the same corrosion environment of the structure or the system in service. As a result, the corrosion of the sensor represents the extent of corrosion of the structure/system being monitored. During the course of corrosion and degradation, there is a rapid change of the surface morphology and the property of the metal, rather than a slow change of the bulk electrical resistance measured by the conventional corrosion sensors. Therefore, the degree of corrosion can be sensitively reflected by the systematic change of the capacitance and the resistance readings from the prototype sensor. To our best knowledge, this type of corrosion sensor based on surface electrical resistance and capacitance measurements has not been reported yet. 
In practice, the sensor can be connected to a wired or wireless network for automatic data acquisition, processing and storage. Multiple sensors can be deployed at varied locations of a structure to provide a comprehensive monitoring network without the need for a site visitation. Thus it is more efficient and cost-saving. This can make it possible to remotely monitor the extent of corrosion of a structure or a system that the sensors are attached to. Figures S1 and S2 in the Supporting Information show an example of the installed corrosion sensors from this study on a steel bridge, the data acquisition and the monitoring system. The sensors can be combined with conventional bulk electrical resistance sensors, which are not sensitive to early-stage corrosion. Thus a monitoring system is formed to examine corrosion of varied stages. The main objective of this study was to develop a sensor system that could sensitively determine the degree of the early-stage corrosion of steel and steel structures during service; thereby, giving a chance to estimate the integrity of the infrastructures and to apply corrosion-control measures timely, so that a catastrophic failure could be prevented.

\section{Results and Discussion}

\subsection{Iron Loss during Corrosion}

A new cylindrical corrosion sensor consisted of a rust-free A36 carbon steel rod in the centre and the 316 stainless steel ring (see the section of Experimental Procedures). Two electrical wires were connected to them respectively. During the corrosion test, rust was visually observed on the A36 steel as early as $2 \mathrm{~h}$ of exposure to an aerated $0.2 \mathrm{M} \mathrm{NaCl}$ solution. In the meantime, the $\mathrm{NaCl}$ solution turned yellowish in colour with suspended small rust particles. After accumulated $225.5 \mathrm{~h}$ in an aerated $0.2 \mathrm{M} \mathrm{NaCl}$ solution, rust was very apparent and had covered a large surface area of the A36 steel rod. However, as expected, no visible corrosion was observed on the 316 stainless steel ring or the stainless steel reference sensor.

During the corrosion process, yellowish iron rust continuously released from the sensor to the $\mathrm{NaCl}$ solution. The amount of iron in the solution was quantified by Atomic Absorption Spectroscopy (AAS) after dissolution of the rust with $10 \%(\mathrm{v} / \mathrm{v})$ nitric acid. The results indicate that $0.16-0.81$ $\mathrm{mg} /$ day of iron was released from the sensor to the solution. As shown in Figure 1, at the end of the test of $225.5 \mathrm{~h}, 3.24 \mathrm{mg}$ of the accumulated iron was in the solution. The corresponding corrosion rate varied between 0.60 and $3.02 \mathrm{~g} /\left(\mathrm{m}^{2}\right.$.day). It should be noted that there was rust on the A36 steel surface in addition to the amount found in the $\mathrm{NaCl}$ solution. The rust was not cleaned from the sensor intentionally to maintain its natural condition during corrosion process. As a result, the overall iron loss and corrosion rate should be greater than that found in the solution as shown in Figure 1. The varied corrosion rate in this study is likely due to different amounts of rust spalling from the sensor from time to time, which can affect the quantity of iron in the solution significantly. However, for the control test of the 316 stainless steel ring alone or the stainless steel reference sensor, the dissolved iron concentration was less than $0.02 \mathrm{mg}$ at the end of $225.5 \mathrm{~h}$ of corrosion, indicating the corrosion was insignificant. 
Figure 1. The iron loss rate and the accumulated iron loss in the solution during the test of the prototype corrosion sensor containing A36 steel in an aerated $0.2 \mathrm{M} \mathrm{NaCl}$ solution.

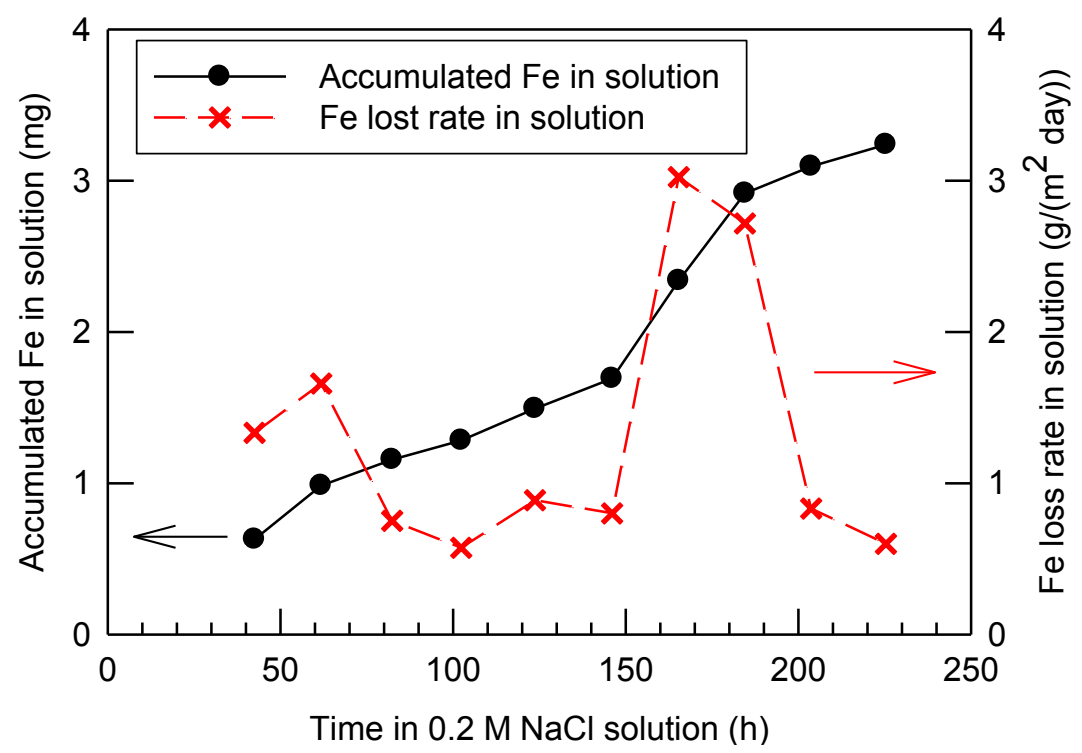

Despite apparent corrosion of the A36 steel rod through AAS measurements and visual observations, the mass of the sensor was maintained almost constant at $25.20 \pm 0.05 \mathrm{~g}$ (i.e., variation was within $\pm 0.2 \%$ ) throughout the test. This result is consistent with Figure 1, in which the iron loss in the solution was within mg range. Based on the reactions (1) to (9), the loss of iron (Fe) from the sensor can be compensated by gains of oxygen and hydrogen atoms in the rust. As a result, mass, as a bulk parameter is not sensitive to evaluate corrosion. On the other hand, the minor change of the mass suggests the early-stage corrosion. The air gap distance between the A36 steel rod and the 316 stainless steel ring of the sensor did not increase significantly, which is an important evidence for the explanation of the electrical resistance and the capacitance changes of the sensor during corrosion in later discussions.

\subsection{Compositions of the Rust}

The corrosion of carbon steel can occur as an electrochemical reaction, with one anodic reaction and one cathodic reaction $[3,15]$. The anodic reaction usually occurs as:

$$
\mathrm{Fe} \rightarrow \mathrm{Fe}^{2+}+2 \mathrm{e}^{-}
$$

The cathodic reaction, however, can be different depending on what is in the environment. This cathodic reaction is the main factor that influences the rate of corrosion $[3,15]$. In an aerated solution it is most likely:

$$
\mathrm{O}_{2}+2 \mathrm{H}_{2} \mathrm{O}+4 \mathrm{e}^{-} \rightarrow 4 \mathrm{OH}^{-}
$$

Combining the cathodic and anodic reactions gives:

$$
2 \mathrm{Fe}+\mathrm{O}_{2}+2 \mathrm{H}_{2} \mathrm{O} \rightarrow 2 \mathrm{Fe}(\mathrm{OH})_{2} \downarrow
$$

As a result, ferrous hydroxide precipitates from the solution. However, dissolved oxygen can oxidize ferrous hydroxide to ferric hydroxide: 


$$
4 \mathrm{Fe}(\mathrm{OH})_{2}+\mathrm{O}_{2}+2 \mathrm{H}_{2} \mathrm{O} \rightarrow 4 \mathrm{Fe}(\mathrm{OH})_{3} \downarrow
$$

Yellowish/brownish rust was observed at the A36 carbon steel surface and in the solution. In addition, black rust was also seen on the A36 steel underneath the yellowish/brownish rust, which is likely magnetite $\left(\mathrm{Fe}_{3} \mathrm{O}_{4}\right)$. The formation of magnetite is due to iron not having enough oxygen present for the reaction [16]. The following additional reactions may occur involving oxidation of iron and producing rusts at the A36 carbon steel surface $[15,17,18]$.

$$
\begin{gathered}
\mathrm{Fe}^{2+} \rightarrow \mathrm{Fe}^{3+}+\mathrm{e}^{-} \\
2 \mathrm{Fe}(\mathrm{OH})_{2} \rightarrow \mathrm{Fe}_{2} \mathrm{O}_{3}+\mathrm{H}_{2} \mathrm{O}+2 \mathrm{H}^{+}+2 \mathrm{e}^{-} \\
4 \mathrm{Fe}(\mathrm{OH})_{2}+\mathrm{O}_{2} \rightarrow 4 \mathrm{FeOOH}+2 \mathrm{H}_{2} \mathrm{O} \\
\mathrm{Fe}^{2+}+8 \mathrm{FeOOH}+2 \mathrm{e}^{-} \rightarrow 3 \mathrm{Fe}_{3} \mathrm{O}_{4}+4 \mathrm{H}_{2} \mathrm{O} \\
2 \mathrm{FeO}+\mathrm{H}_{2} \mathrm{O} \rightarrow \mathrm{Fe}_{2} \mathrm{O}_{3}+2 \mathrm{H}^{+}+2 \mathrm{e}^{-}
\end{gathered}
$$

To examine the crystalline compositions of the iron rust on the A36 steel surface, x-ray diffraction (XRD) analysis was performed with $\mathrm{CuK \alpha}$ radiation. Figure 2a shows the XRD spectrum of uncorroded A36 steel. Figure $2 \mathrm{~b}$ shows the XRD spectrum of the corroded A36 steel soaked in an aerated $0.2 \mathrm{M} \mathrm{NaCl}$ solution for $225.5 \mathrm{~h}$. Three types of crystalline substances were found on the corroded steel surface according to their characteristic diffraction patterns [19,20], which were 1: iron, 2: lepidocrocite, and 3: magnetite.

Figure 2. XRD patterns of the (a) uncorroded and (b) corroded A36 steel samples. The identified crystals are 1: iron, 2: lepidocrocite, 3: magnetite.

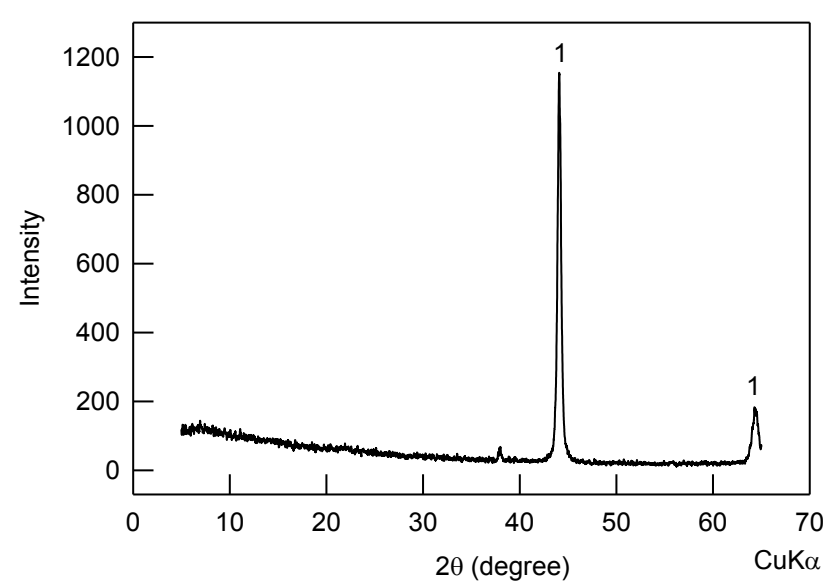

(a)

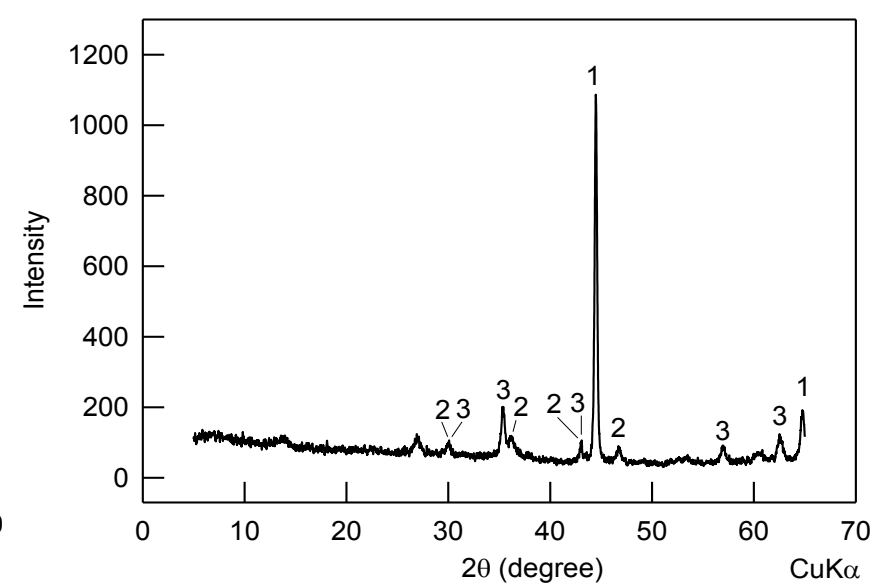

(b)

Consistently, it has been reported that the rust formed on steel surface is a mixture of lepidocrocite $(\gamma-\mathrm{FeOOH})$, magnetite $\left(\mathrm{Fe}_{3} \mathrm{O}_{4}\right)$, hematite $\left(\alpha-\mathrm{Fe}_{2} \mathrm{O}_{3}\right)$, goethite $(\alpha-\mathrm{FeOOH})$, and amorphous iron oxide [21-24], although only the first two were found in this study. To make the study more general, the resistivity and the dielectric constant of the common rust materials, along with iron and air are listed in Table 1. 
Table 1. Electrical resistivity and the dielectric constant of materials related to iron rust at ambient temperature.

\begin{tabular}{|c|c|c|c|c|c|c|c|}
\hline Materials & $\alpha-\mathrm{Fe}_{2} \mathrm{O}_{3}$ & $\gamma$-FeOOH & $\mathrm{Fe}_{3} \mathrm{O}_{4}$ & a-FeOOH & $\begin{array}{c}\text { Amorphous } \\
\mathrm{Fe}_{2} \mathrm{O}_{3} \\
\end{array}$ & Iron & Air \\
\hline $\begin{array}{l}\text { Electrical } \\
\text { resistivity } \\
\rho(\Omega \cdot \mathrm{m})\end{array}$ & $\begin{array}{c}(1.58-5.62) \times 10^{4} \\
{[25]}\end{array}$ & $\begin{array}{c}(0.20-0.80) \times 10^{5} \\
{[26]}\end{array}$ & $\begin{array}{c}1.58 \times 10^{-4}-0.1 \\
{[27]}\end{array}$ & $\begin{array}{c}(1.30-2.33) \times 10^{5} \\
{[26]}\end{array}$ & $\begin{array}{c}2.12 \times 10^{3} \\
{[28]}\end{array}$ & $1.0 \times 10^{-7}$ & $4 \times 10^{13}$ \\
\hline $\begin{array}{l}\text { Dielectric } \\
\text { constant } \varepsilon\end{array}$ & 12 & 2.6 [29] & 20 & $11[30]$ & 4.5 & - & 1 \\
\hline
\end{tabular}

Note: Data are from reference [31] unless otherwise noted.

\subsection{Electrical Resistance of the Sensor}

Figure 3 shows the electrical resistance of the sensor in parallel (i.e., the built-in measurement mode of a resistance, capacitance and inductance (RCL) meter) with the extension of corrosion time in the $\mathrm{NaCl}$ solution. In Figure 3, during the course of corrosion, the resistance gradually decreased following an apparent trend. At the end of the corrosion test of $225.5 \mathrm{~h}$, the normalized resistance $\left(R / R_{0}\right)$ decreased from 1.0 to 0.74 , a decline of $26 \%$.

Figure 3. Normalized electrical resistance $\left(R / R_{0}\right)$ of the prototype sensors $v s$. the accumulated time in an aerated $0.2 \mathrm{M} \mathrm{NaCl}$ solution.

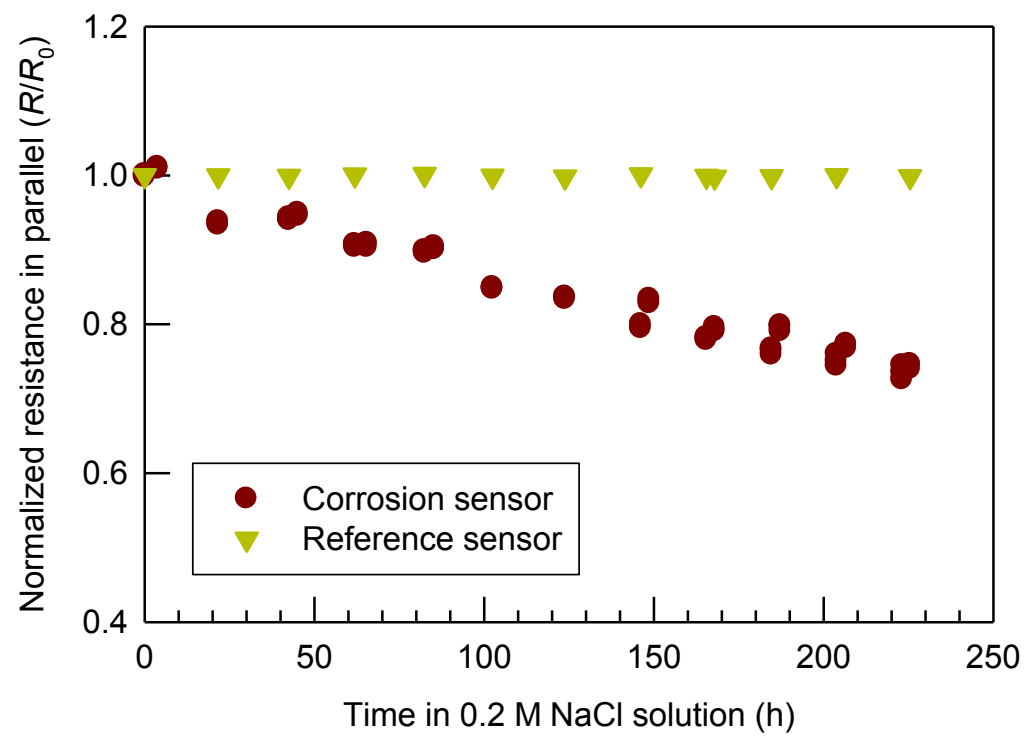

The electrical resistance for a coaxial cylinder can be expressed by the following equation.

$$
R=\frac{\rho}{2 \pi h} \ln \left(\frac{b}{a}\right)
$$

where $R=$ electrical resistance of a material $(\Omega) ; \rho=$ electrical resistivity of the material $(\Omega \cdot \mathrm{m})$; $h=$ height of the cylinder sensor $(\mathrm{m}) ; b=$ inner radius of the 316 stainless steel ring $(\mathrm{m}) ; a=$ radius of the A36 steel rod (m).

After corrosion, the multi-material resistor (iron rust on A36 steel surface and the air gap) can be treated as resistance in-series to calculate the overall resistance of the sensor, 


$$
R=\frac{1}{2 \pi h}\left[\rho_{1} \ln \frac{a+\delta}{a-\delta(1-\varphi)}+\rho_{2} \ln \frac{b}{a+\delta}\right]
$$

where $\rho_{1}=$ equivalent electrical resistivity of the porous iron rust on the A36 steel rod surface $(\Omega \cdot \mathrm{m})$; $\rho_{2}=$ electrical resistivity of the air gap between the iron rust on the A36 steel rod surface and the 316 stainless steel ring $(\Omega \cdot \mathrm{m}) ; \delta=$ average thickness of the iron rust on the A36 steel rod surface $(\mathrm{m})$; $\varphi=$ average porosity of the iron rust on the A36 steel rod surface.

The resistance of a new sensor (before corrosion) is mainly due to the air gap between the central cylindrical A36 steel rod and the 316 stainless steel ring (see the section of Experimental Procedures). Air has an electrical resistivity of $4 \times 10^{13} \Omega \cdot \mathrm{m}$ [31]. This is different from the conventional corrosion sensors, which measure the bulk electrical resistance of the metal. When corrosion of the steel rod happened, rust formed a porous and loose structure [22] extended from the A36 steel surface to the surrounding air. As a result, the rust took a partial space that was previously occupied by air. In other words, after corrosion the gap between the A36 steel rod and the 316 stainless steel ring was partially filled with porous rust (small portion) and air (big portion). Equation (11) shows the overall resistance of the sensor as a multi-material resistor (iron rust and air gap). As mentioned earlier, the iron rust is a mixture of lepidocrocite $(\gamma-\mathrm{FeOOH})$ and magnetite $\left(\mathrm{Fe}_{3} \mathrm{O}_{4}\right)$ as shown in Figure $2 \mathrm{~b}$, along with reported hematite $\left(\alpha-\mathrm{Fe}_{2} \mathrm{O}_{3}\right)$, goethite $(\alpha-\mathrm{FeOOH})$ and amorphous iron oxide [21-24]. Their electrical resistivity is shown in Table 1. As can be seen, the electrical resistivity of the rust components is at least eight orders of magnitude lower than air. According to Equation (11), a lower electrical resistivity has smaller resistance. Consequently, the electrical resistance decreases with the time or the extent of corrosion. Different from conventional corrosion sensors, which detect an increase in the bulk electrical resistance of iron with corrosion [8,9], the cylindrical sensor explored in this study examined the A36 surface property and morphology changes. Thus it is more sensitive to monitor the early-stage corrosion. In addition, the sensitivity of the sensor can be fine-tuned by optimizing the values of $a$ and $b$. The closer the values of $a$ and $b$, the greater sensitivity of the corrosion sensor is expected to have.

Although spalling of rust from the sensor could enlarge the air gap between the A36 steel rod and the 316 stainless steel ring, the insignificant mass-loss result (i.e., mass change $\leq 0.2 \%$ or $187.7 \mathrm{~g} / \mathrm{m}^{2}$ ) indicates this was not the case during the testing period of early-stage corrosion. However, if significant spalling of rust happens (i.e., $a-\delta(1-\varphi)$ becomes much small) and thus the air gap between the A36 steel rod and the 316 stainless steel ring increases, the trend of electrical resistivity can be reversed (i.e., electrical resistance increases with time instead), suggesting much severe corrosion, which can be regarded as middle- or late-stage corrosion. This turning point can be used to rank the risk level of corrosion. In contrast, the electrical resistance of the stainless steel reference sensor was stable, as shown in Figure 3. In practice, the reference sensors can be used to normalize the baseline signal of electrical resistances including the effects of air moisture and temperature, in order to distinguish the electrical resistance changes caused by rust formation on the steel surface.

\subsection{Capacitance of the Sensor}

In addition to the electrical resistances, the capacitance of the sensor during corrosion was also examined. Again, the capacitance was from the built-in parallel measurement mode of the RCL meter. Figure 4 shows the change of the capacitance vs. accumulated time of corrosion in an aerated 
$0.2 \mathrm{M} \mathrm{NaCl}$ solution. A positive trend of the capacitance with the extent of corrosion was observed. More specifically, the normalized capacitance $\left(C / C_{0}\right)$ increased from 1.0 at the beginning to 1.46 after $225.5 \mathrm{~h}$. In other words, the capacitance had an increase of $46 \%$.

Figure 4. Normalized capacitance $\left(C / C_{0}\right)$ of the prototype sensors $v s$. the accumulated time in an aerated $0.2 \mathrm{M} \mathrm{NaCl}$ solution.

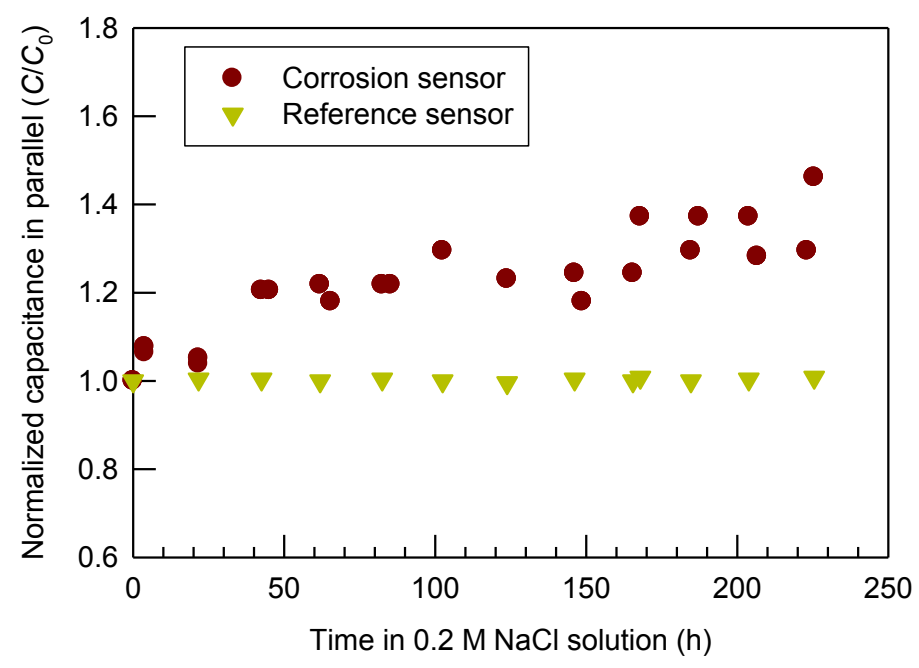

The capacitance of an infinite cylindrical sensor, neglecting the fringing effect, can be calculated from the following equation [32] (see the Supporting Information of a reference equation of the capacitance with fringing effect considered),

$$
C=\frac{2 \pi \varepsilon_{0} h * \varepsilon}{\ln \left(\frac{b}{a}\right)}
$$

where $C=$ capacitance $(\mathrm{pF}) ; \varepsilon_{0}=$ free space permittivity, $8.85 \mathrm{pF} / \mathrm{m} ; h=$ height of the cylinder sensor (m); $\varepsilon=$ dielectric constant of the material(s) between the A36 steel rod and the 316 stainless steel ring.

Before corrosion, air was between the A36 steel rod and the 316 stainless steel ring. Air has a dielectric constant $\varepsilon$ of 1 [31]. After corrosion, rust was formed at the A36 steel surface. It means the space between the A36 steel rod and the 316 stainless steel ring was filled with both rust and air, although rust has a much smaller volume than air in this case. The multi-material capacitor (iron rust on A36 steel surface and the air gap) can be treated as capacitors-in-series to calculate the overall capacitance of the sensor,

$$
C=2 \pi \varepsilon_{0} h \frac{\varepsilon_{1} \varepsilon_{2}}{\varepsilon_{1} \ln \left(\frac{b}{a+\delta}\right)+\varepsilon_{2} \ln \left(\frac{a+\delta}{a-\delta(1-\varphi)}\right)}
$$

where $\varepsilon_{1}=$ equivalent dielectric constant of the porous iron rust on the A36 steel rod surface; $\varepsilon_{2}=$ dielectric constant of the air gap between the iron rust on the A36 steel rod surface and the 316 stainless steel ring.

As corrosion takes place, iron rust gradually grows on the steel surface (i.e., increase in $\delta$ from zero initially). As shown in Table 1 , the dielectric constant $\varepsilon_{1}$ of the substances composing the iron 
rust ranges from 2.6 to 20, much greater than air. Equation (13) shows the overall capacitance $C$ is proportional to $\varepsilon_{1}$. An increase in $\varepsilon_{1}$ and/or $\delta$ raises the capacitance of the corrosion sensor, although further sensitivity analysis of Equation (13) indicates that $C$ is much more sensitive to $\varepsilon_{1}$ than $\delta$. However, spalling of the rust from the A36 steel and thus a decrease in $a-\delta(1-\varphi)$ was insignificant during the early-stage corrosion, because of the measured almost constant mass of the sensor during the test. Consequently, a higher capacitance reading reflects more rust formation at the A36 steel surface of the sensor during the early-stage corrosion. However, if spalling of the rust is significant enough (i.e., $a-\delta(1-\varphi)$ becomes much small), a decrease in capacitance would indicate severe corrosion, which can be regarded as middle- or late-stage corrosion. Same as the resistance, this turning point of capacitance trend (i.e., decrease in capacitance with time instead) can be used to rank the risk level of corrosion. Again, the reference sensor had little change in capacitance with corrosion time as shown in Figure 4. The reference sensor can be used to normalize the environmental factors (e.g., air moisture and temperature) caused capacitance changes other than corrosion.

The configuration of a short cylindrical sensor (height is comparable to diameter/gap) was designed intentionally to enhance the sensitivity to the change of surface property. In other words, the capacitor of shorter height is more sensitive to the changes of the dielectric constant $\varepsilon$ and the surface morphology of the sensor during the course of corrosion, because of greater specific surface area. Although Equation (13) does not consider the effect of fringe field, which lacks of a reliable equation to quantify, it does describe the fundamental relationship between capacitance $C$ and the dielectric constant $\varepsilon_{1}$ and the average thickness of the rust layer $\delta$, which is verified by the experimental results from this study.

During corrosion monitoring of a structure, the empirical equations can be developed based on laboratorial tests in an environmental chamber through multiple regressions, i.e., the differences in resistance and capacitance readings between the corrosion and the reference sensors as a function of the parameters including the extent of corrosion (iron loss), temperature and moisture level. The equations are used to interpret the resistance and capacitance data from the site along with the site's temperature and moisture information. As a result, the extent of corrosion can be determined by plugging the site's temperature and moisture data in the equation and then solving the extent of corrosion numerically. In addition, depending on the specific requirement of a monitoring site, a feature of periodic sleep and wakeup time can be adopted to save energy and cost.

In order to mitigate potential fouling problem of the sensors on site, paired corrosion and reference sensors are installed side-by-side with the identical coating/passivation in order to minimize the uncertainty brought by location-dependent fouling issue caused by such as particles and debris. Special cares are taken to ensure the orientation of the sensors is not prone to accumulate dust; while rainfall and snow melting can help clean the sensors. After normalizing the capacitance of both of the corrosion and the reference sensors, the systematic differences in resistance and capacitance readings between the corrosion and the reference sensors are expected to reflect the extent of corrosion. In addition, sufficient paired corrosion and reference sensors are attached to the structure being monitored. Statistical analysis is an important part of the corrosion monitoring network. The averaged differences in resistance and capacitance readings between the corrosion and the reference sensors can further minimize the uncertainty caused by fouling problem. 


\section{Experimental Procedures}

\subsection{Cylindrical Capacitor}

ASTM A36 steel was used in this study. It contains at least $99.05 \%$ of $\mathrm{Fe}$, and max $0.26 \% \mathrm{C}$, $\max 0.04 \% \mathrm{P}, \max 0.05 \% \mathrm{~S}, \max 0.40 \% \mathrm{Si}$, and $\max 0.20 \% \mathrm{Cu}$ (by wt) [33]. As shown in Figure 5, a cylindrical capacitor was created with the inner cylinder made from A36 carbon steel rod and the outer ring made from 316 stainless steel. Each of them had a height of $0.64 \mathrm{~cm}$. The inner cylinder had a diameter of $1.27 \mathrm{~cm}$ while the outer ring had an outer diameter of 2.64 and inner diameter of $2.22 \mathrm{~cm}$. The A36 carbon steel was polished by a $3 \mathrm{M}^{\circledR} 80$ grit then a $3 \mathrm{M}^{\circledR} 600$ grit sandpaper. Two wires were attached to the capacitor, one was soldered to the base of the center A36 steel rod and the other was welded to the base of the outer ring of the 316 stainless steel. A bridge made of a glass substrate epoxy resin insulator from the circuit board (BM-FR4-1SS2, T-Tech Inc., Norcross, GA, USA) was adhered on the bottom of both the inner cylinder and the ring through a waterproof epoxy (15206 Anchor-Tite, Super Glue Corporation, Rancho Cucamonga, CA, USA) to fix their relative positions. Finally, the waterproof epoxy was used to cover the connections of these wires as well as the base of the sensor to prevent corrosion of the connections and the wires, as well as to insulate the sensor from the infrastructure to be monitored. The uncovered A36 steel had a surface area of about $2.66 \mathrm{~cm}^{2}$, which was subject to corrosion.

Similarly, a reference sensor was made following the same procedures and dimensions except replacing the A36 carbon steel rod with a 316 stainless steel rod of the same dimensions, and then being welded to connect to the circuit-board bridge. The connections including welding points of the reference sensor were coated with the waterproof epoxy to prevent corrosion. The reference sensor was served to draw baseline information by addressing environmental conditions such as the temperature and the moisture level of air other than corrosion.

Figure 5. Diagram of the prototype corrosion sensor made of a cylindrical capacitor used for corrosion monitoring.

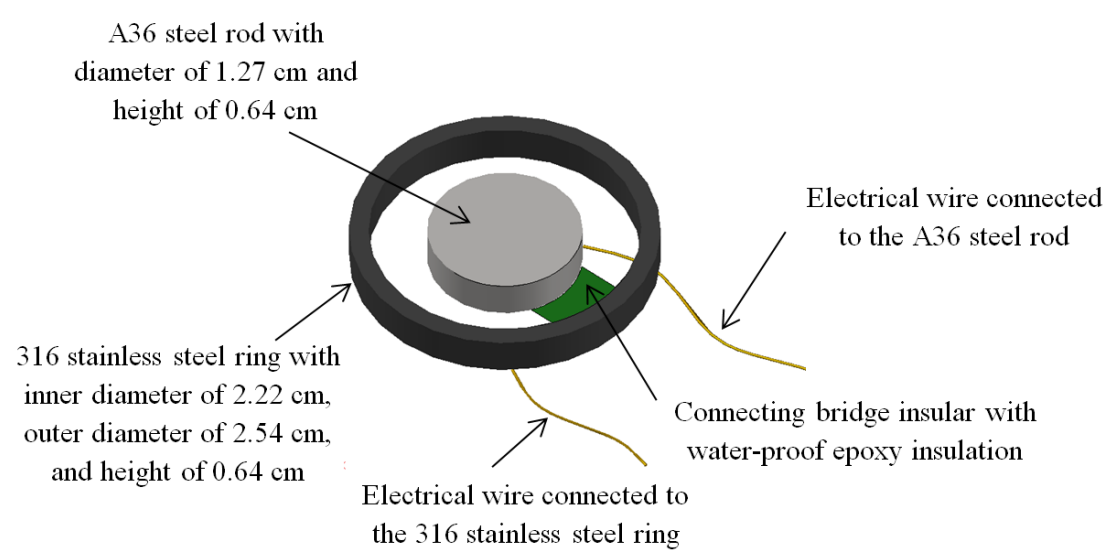

\subsection{Corrosion Test}

A 500-mL 0.2 M sodium chloride solution at $20 \pm 1{ }^{\circ} \mathrm{C}$ was used for corrosion testing. An air pump (Aqua Culture ${ }^{\circledR}$, China) with a flow rate of $\sim 1.2 \mathrm{~L} / \mathrm{min}$ was continuously bubbling air through a 
diffuser to the solution to provide oxygen for the corrosion process (Figure 6). The air diffuser was porous sandstone. The dissolved oxygen level of the $\mathrm{NaCl}$ solution was maintained at around $8.8 \mathrm{mg} / \mathrm{L}$. The corrosion sensor was submerged in the sodium chloride solution above the air diffuser. Every day during the course of the test, the sensor was removed from the solution, rinsed with DI water, dried at room temperature for 2-3 h, and then tested with an automatic RCL meter (PM6303A, Fluke Corporation, Everett, WA, USA). At each measurement, multiple readings from the RCL meter with time were recorded until stable readings obtained, indicating the senor was dried at equilibrium with air moisture. As a result, the sensor experienced periodically wet/dry cycles twice a day for total 11 days. A new $0.2 \mathrm{M}$ sodium chloride solution was freshly made daily. The accumulated corrosion time of the senor in the sodium chloride solution was $225.5 \mathrm{~h}$. As a control test, a 316 stainless steel ring and the reference sensor was soaked in an aerated $500-\mathrm{mL} 0.2 \mathrm{M}$ sodium chloride solution separately to investigate the degree of corrosion of the 316 stainless steel and the reference sensor, respectively.

Figure 6. The corrosion testing device. The prototype cylindrical sensor was submerged in an aerated $0.2 \mathrm{M} \mathrm{NaCl}$ solution with an air diffuser underneath.

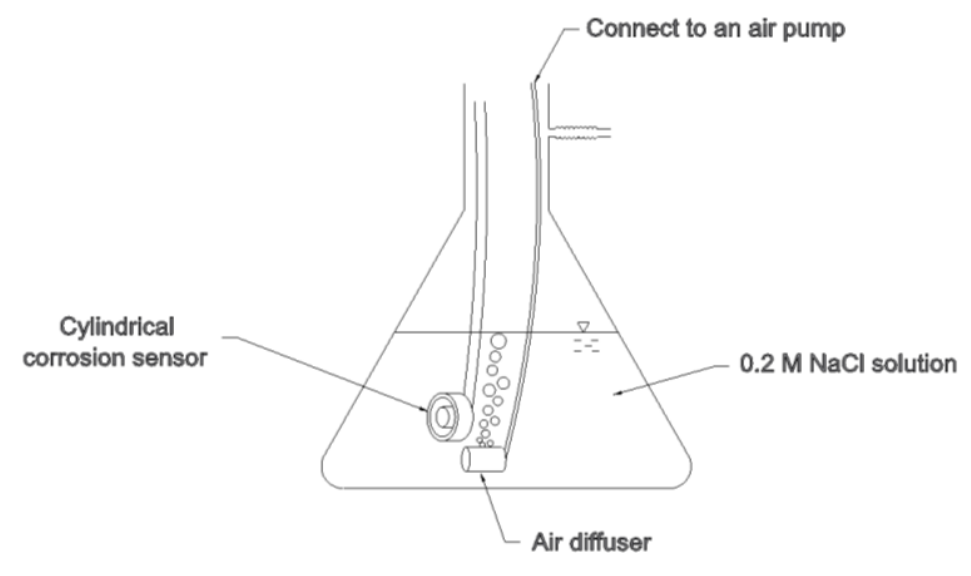

\subsection{Sensor Measurements}

The RCL meter was used to measure the resistance and the capacitance of the prototype corrosion sensors or the reference sensors. The readings were obtained in parallel mode, which was one of the built-in functions of the meter. The meter used an AC power with frequency of $1 \mathrm{kHz}$ and a voltage of $1.9 \mathrm{~V}$ for the measurements to minimize electrolysis and electrode polarization problems brought by a DC power. With an increase in AC frequency, the interval between successive anodic and cathodic half-cycles becomes progressively shorter [34]. Thus the electrolytic reactions do not have enough time to complete, and it even increases the potential to reverse the reactions of the immediate prior cycle. When the power frequency is high enough (e.g., $1 \mathrm{kHz}$ [35]), no electrolysis of AC was observed, because all current would pass via the double layer of the electrodes [34,36]. The RCL meter took five measurements: a reference reading, a voltage reading at the phase angle of $0^{\circ}$ and $90^{\circ}$, and a current reading at the phase angle of $0^{\circ}$ and $90^{\circ}$, it then calculated the values for resistance and capacitance (which could be in either series and parallel) based on this model. It was decided to use the parallel mode of this meter as the focus of these measurements is on a capacitor, so all the measurements in this study were found using the parallel mode. In real time monitoring of an infrastructure, instead of using a RCL meter, the corrosion sensor data acquisition algorithm, coded in 
VbScript, running under a Windows XP embedded computer, produced one data file for each sensor at 30 min interval (see Supporting Information).

In addition, the mass of the dried sensor was examined by a digital balance (ESA-3000, Brecknell, Fairmont, MN, USA) with a precision of $0.05 \mathrm{~g}$. The initial weight of the prototype corrosion sensor was $25.20 \mathrm{~g}$. For the prototype corrosion sensor, the initial resistance $\left(R_{0}\right)$ was $48.63 \times 10^{6} \Omega$; the initial capacitance $\left(C_{0}\right)$ was $7.8 \mathrm{pF}$ before corrosion test. For the stainless steel reference sensor, the initial resistance was $37.66 \times 10^{6} \Omega$; the initial capacitance $\left(C_{0}\right)$ was $24.9 \mathrm{pF}$. The difference of the initial readings between the corrosion and the reference sensor is likely due to welding connection to 316 stainless steel rod (rather than soldering to A36 carbon steel), because soldering is not feasible for stainless steel.

\subsection{Sample Analyses}

After the corrosion sensor was removed from the $\mathrm{NaCl}$ solution, the daily solution samples were acidified with ACS grade nitric acid from Mallinckrodt to $10 \%(\mathrm{v} / \mathrm{v})$ to dissolve the iron rust in the solution. AAS (AAnalyst 200, PerkinElmer, Waltham, MA, USA) was utilized to measure the total dissolved iron in the solution.

The crystalline substances on both of the corroded and uncorroded A36 steel surface were examined by XRD with $\mathrm{CuK} \alpha$ radiation (APD3520, Philips, Amsterdam, The Netherlands). For the uncorroded sample, a piece of the A36 steel of $1.27 \mathrm{~cm}$ diameter and $0.2 \mathrm{~cm}$ thickness was polished by a $3 \mathrm{M}^{\circledR} 80$ grit then a $3 \mathrm{M}^{\circledR} 600$ grit sandpaper. The steel sample was cleaned by blowing thoroughly with compressed nitrogen. For the corroded sample, the same polishing procedures were followed as the uncorroded sample, then the A36 steel sample was submerged in an aerated $500-\mathrm{mL} 0.2 \mathrm{M}$ sodium chloride solution for $225.5 \mathrm{~h}$. The corroded steel sample was rinsed with DI water and dried in air for XRD examination.

\section{Conclusions}

Automatic detection of the early-stage corrosion is highly important to find the potential problem and apply corrosion control techniques timely for safety and integrity concerns. This study explored an innovative cylindrical corrosion sensor made of A36 carbon steel (representing the material of a structure or a system to be monitored for corrosion) and a 316 stainless steel ring (representing an inert material of low corrosion potential). A capacitor was formed with both conductors separated by air. The sensor is more sensitive than the conventional corrosion sensors based on the bulk electrical-resistance method. After corrosion in an aerated $0.2 \mathrm{M} \mathrm{NaCl}$ solution for $225.5 \mathrm{~h}$, the cylindrical corrosion sensor has shown a systematic decrease in the normalized electrical resistance $\left(R / R_{0}\right)$ from 1.0 to 0.74 . Meanwhile, the normalized capacitance $\left(C / C_{0}\right)$ of the sensor increased from 1.0 to 1.46 . However, the weight change of the sensor was within $0.2 \%$ (or $187.7 \mathrm{~g} / \mathrm{m}^{2}$ ), an indication of the early-stage corrosion. In the same time, the reference senor, which was not subject to corrosion apparently, showed a stable normalized reading around 1.0. XRD result shows that the rust contained lepidocrocite and magnetite. By attaching the paired corrosion and reference sensors with the identical passivation/coating to a steel structure in air, the extent of corrosion of the structure can be directly 
reflected by the electrical resistance decrease and/or capacitance increase of the sensor with time during the early-stage corrosion.

\section{Acknowledgments}

The research project was funded by the US Army Engineer Research and Development Centre, Construction Engineering Research Laboratory through the contract of W9132T-10-2-0056. The authors also thank Robert Tilbury and Mengwei Li for their help for this project. XRD was performed in the Argast Family Instrumentation and Analysis Lab at the Indiana University-Purdue University Fort Wayne.

\section{Author Contributions}

In this paper, Dong Chen and Max Yen formulated the research ideas and the test plan. Paul Lin designed and built the data collection, the processing and the storage system. Steve Groff carried out the corrosion experiments in lab and consolidated the data. Richard Lampo, Michael McInerney and Jeffrey Ryan supervised the research, provided the technical guidance and prepared the experimental materials.

\section{Nomenclature}

$a \quad$ radius of the $\mathrm{A} 36$ steel $\operatorname{rod}(\mathrm{m})$

$b \quad$ inner radius of the 316 stainless steel ring $(\mathrm{m})$

C sensor's capacitance $(\mathrm{pF})$

$h \quad$ height of the cylinder sensor $(\mathrm{m})$

$R \quad$ electrical resistance of a material $(\Omega)$

$\varepsilon_{0} \quad$ free space permittivity, $8.85 \mathrm{pF} / \mathrm{m}$

$\varepsilon_{1} \quad$ equivalent dielectric constant of the porous iron rust on the A36 steel rod surface

dielectric constant of the air gap between the iron rust on the A36 steel rod surface and the 316 stainless steel ring

$\rho_{1} \quad$ equivalent electrical resistivity of the porous iron rust on the A36 steel rod surface $(\Omega \cdot \mathrm{m})$

electrical resistivity of the air gap between the iron rust on the A36 steel rod surface and

$\rho_{2} \quad$ the 316 stainless steel $\operatorname{ring}(\Omega \cdot \mathrm{m})$

$\delta \quad$ average thickness of the iron rust on the A36 steel rod surface (m)

$\varphi \quad$ average porosity of the iron rust on the A36 steel rod surface

\section{Conflicts of Interest}

The authors declare no conflicts of interest.

\section{References}

1. Uhlig, H.H.; Revie, R.W. Corrosion and Corrosion Control: An Introduction to Corrosion Science and Engineering; John Wiley \& Sons: New York, NY, USA, 1985. 
2. Borgard, B.; Warren, C.; Somayaji, S.; Heidersbach, R. Corrosion Rates of Steel in Concrete; ASTM STP 1065; Berke, N.S., Chaker, V., Whiting, D., Eds.; American Society for Testing and Materials: Philadelphia, PA, USA, 1990; pp. 174-188.

3. Fontana, M.G.; Greene, N.D. Corrosion Engineering; McGraw-Hill: New York, NY, USA, 1967; Chapter 1.

4. Soares, C.G.; Garbatov, Y.; Zayed, A. Effect of environmental factors on steel plate corrosion under marine immersion conditions. Corros. Eng. Sci. Technol. 2011, 46, 524-541.

5. Montemor, M.F.; Simões, A.M.P.; Ferreira, M.G.S. Chloride-induced corrosion on reinforcing steel: From the fundamentals to the monitoring techniques. Cem. Concr. Compos. 2003, 25, 491-502.

6. Haleem, S.M.A.E.; Wanees, S.A.E.; Aal, E.E.A.E.; Diab, A. Environmental factors affecting the corrosion behavior of reinforcing steel II. Role of some anions in the initiation and inhibition of pitting corrosion of steel in $\mathrm{Ca}(\mathrm{OH})_{2}$ solutions. Corros. Sci. 2010, 52, 292-302.

7. Morris, W.; Vico, A.; Vázquez, M. Chloride induced corrosion of reinforcing steel evaluated by concrete resistivity measurements. Electrochim. Acta 2004, 49, 4447-4453.

8. Li, S.Y.; Kim, Y.G.; Jung, S.; Song, H.S.; Lee, S.M. Application of steel thin film electrical, resistance sensor for in situ corrosion monitoring. Sens. Actuators B 2007, 120, 368-377.

9. Zivica, V. Utilisation of electrical resistance method for the evaluation of the state of steel reinforcement in concrete and the rate of its corrosion. Constr. Build. Mater. 2000, 14, 351-358.

10. Reading, M.S.; Denzine, A.F. A critical comparison of corrosion monitoring techniques used in industrial applications. In Industrial Corrosion and Corrosion Control Technology; Shalaby, H.M., Al-Hashem, A., Lowther, M., Al-Besharah, J., Eds.; Kuwait Institute for Scientific Research: Kuwait City, Kuwait, 1996; pp. 511-519.

11. Popova, A.; Veleva, S.; Raicheva, S. Kinetic approach to mild steel corrosion. React. Kinet. Catal. Lett. 2005, 85, 99-105.

12. Fontana, M.G. Corrosion Engineering, 3rd ed.; McGraw Hill: New York, NY, USA, 1987.

13. Sen, R.; Liby, L.; Mullins, G. Strengthening steel bridge sections using CFRP laminates. Compos. Part B Eng. 2001, 32, 309-322.

14. Tavakkolizadeh, M.; Saadatmanesh, H. Fatigue strength of steel girders strengthened with carbon fiber reinforced polymer patch. J. Struct. Eng. ASCE 2003, 129, 186-196.

15. Evans, U.R.; Taylor, C.A.J. Mechanism of atmospheric rusting. Corros. Sci. 1972, 12, 227-246.

16. Haupt, S.; Strehblow, H.H. Corrosion, layer formation, and oxide reduction of passive iron in alkaline solution: A combined electrochemical and surface analytical study. Langmuir 1987, 3, 873-885.

17. Abd El-Maksoud, S.A. The effect of organic compounds on the electrochemical behavior of steel in acidic media. Int. J. Electrochem. Sci. 2008, 3, 528-555.

18. Broomfield, J.P. Corrosion of Steel in Concrete: Understanding, Investigation and Repair; Taylor \& Francis: London, UK, 2007; Chapter 2.

19. Roberts, W.L.; Campbell, T.J.; Rapp, G.R., Jr. Encyclopedia of Minerals, 2nd ed.; Chapman \& Hall: New York, NY, USA, 1990.

20. Mineral Powder Diffraction File: Data Book; JCPDS-International Centre for Diffraction Data; American Society for Testing and Materials: Swarthmore, PA, USA, 1986. 
21. Suzuki, I.; Masuko, N.; Hisamatsu, Y. Electrochemical properties of iron rust. Corros. Sci. 1979, 19, 521-535.

22. González, J.A.; Miranda, J.M.; Otero, E.; Feliu, S. Effect of electrochemically reactive rust layers on the corrosion of steel in a $\mathrm{Ca}(\mathrm{OH})_{2}$ solution. Corros. Sci. 2007, 49, 436-448.

23. Nishimura, N.; Katayama, H.; Noda, K.; Kodama, T. Electrochemical behavior of rust formed on carbon steel in a wet/dry environment containing chloride ions. Corrosion 2000, 56, 935-941.

24. Yuan, J.; Wu, X.; Wang, W.; Zhu, S.; Wang, F. The effect of surface finish on the scaling behavior of stainless steel in steam and supercritical water. Oxid. Met. 2013, 79, 541-551.

25. Varshney, D.; Yogi, A. Structural and electrical conductivity of Mn doped hematite $\left(\alpha-\mathrm{Fe}_{2} \mathrm{O}_{3}\right)$ phase. J. Mol. Struct. 2011, 995, 157-162.

26. Lair, V.; Antony, H.; Legrand, L.; Chaussé, A. Electrochemical reduction of ferric corrosion products and evaluation of galvanic coupling with iron. Corros. Sci. 2006, 48, 2050-2063.

27. Ltai, R.; Shibuya, M.; Matsumura, T.; Ishi, G. Electrical resistivity of magnetite anodes. J. Electrochem. Soc. 1971, 118, 1709-1711.

28. Akl, A.A. Microstructure and electrical properties of iron oxide thin films deposited by spray pyrolysis. Appl. Surf. Sci. 2004, 221, 319-329.

29. Glotch, T.D.; Rossman, G.R. Mid-infrared reflectance spectra and optical constants of six iron oxide/oxyhydroxide phases. Icarus 2009, 204, 663-671.

30. Filius, J.D.; Lumsdon, D.G.; Meeussen, J.C.L.; Hiemstra1, T.; van Riemsdijk, W.H. Adsorption of fulvic acid on goethite. Geochim. Cosmochim. Acta 2000, 64, 51-60.

31. Haynes, W.M. CRC Handbook of Chemistry and Physics, 91st ed.; CRC Press: Boca Raton, FL, USA, 2010.

32. Basu, B.N. Electromagnetic Theory and Applications in Beam-Wave Electronics; World Scientific: Singapore, Singapore, 1996.

33. Standard Specification for Carbon Structural Steel; ASTM Standard A36/A36M-08; ASTM International: West Conshohocken, PA, USA, 2008.

34. Park, J.C.; Lee, M.S.; Han, D.W.; Lee, D.H.; Park, B.J.; Lee, I.S.; Uzawa, M.; Aihara, M.; Takatori, K. Inactivation of Vibrio parahaemolyticus in effluent seawater by alternating-current treatment. Appl. Environ. Microbiol. 2004, 70, 1833-1835.

35. Kortum, G. Treatise on Electrochemistry; Elsevier: London, UK, 1965.

36. Fernandes, S.Z.; Mehendale, S.G.; Verkatachalam, S. Influence of frequency of alternating current on the electrochemical dissolution of mild steel and nickel. J. Appl. Electrochem. 1980, 10, 649-654.

(C) 2014 by the authors; licensee MDPI, Basel, Switzerland. This article is an open access article distributed under the terms and conditions of the Creative Commons Attribution license (http://creativecommons.org/licenses/by/3.0/). 